Original paper

\title{
Infrared camera assessment of skin surface temperature - Effect of emissivity
}

\author{
V. Bernard*, E. Staffa, V. Mornstein, A. Bourek \\ Masaryk University, Faculty of Medicine, Department of Biophysics, Kamenice 3, 62500 Brno, Czech Republic
}

\section{A R T I C L E I N F O}

\section{Article history:}

Received 24 April 2012

Received in revised form

25 September 2012

Accepted 28 September 2012

Available online 18 October 2012

\section{Keywords:}

Emissivity

Infrared thermography

Skin

Temperature

\begin{abstract}
A B S T R A C T
Infrared thermoimaging is one of the options for object temperature analysis. Infrared thermoimaging is unique due to the non-contact principle of measurement. So it is often used in medicine and for scientific experimental measurements. The presented work aims to determine whether the measurement results could be influenced by topical treatment of the hand surface by various substances. The authors attempted to determine whether the emissivity can be neglected or not in situations of topical application of substances such as ultrasound gel, ointment, disinfection, etc. The results of experiments showed that the value of surface temperature is more or less distorted by the topically applied substance. Our findings demonstrate the effect of emissivity of applied substances on resulting temperature and showed the necessity to integrate the emissivity into calculation of the final surface temperature. Infrared thermoimaging can be an appropriate method for determining the temperature of organisms, if this is understood as the surface temperature, and the surrounding environment and its temperature is taken into account.
\end{abstract}

(c) 2012 Associazione Italiana di Fisica Medica. Published by Elsevier Ltd. All rights reserved.

\section{Introduction}

Electromagnetic radiation is ubiquitous and may be classified according to its frequency or wavelength. The radiation restricted to the wavelengths from $760 \mathrm{~nm}$ to $1 \mathrm{~mm}$ is referred to as infrared radiation or "thermal radiation". This wavelength range is usually further sub-divided into three regions: near infrared (wavelengths $760 \mathrm{~nm}$ to approximately $2.5 \mu \mathrm{m}$ ), middle infrared (wavelengths 2.5 to approximately $50 \mu \mathrm{m}$ ) and far infrared (wavelengths $50 \mu \mathrm{m}-$ $1 \mathrm{~mm}$ ). Infrared radiation is emitted as a result of changes in atomic and molecular vibration and rotation states by any matter with a temperature higher than several $K$.

Heat may be transferred by conduction, convection and radiation. The last option is used by thermographic imaging systems.

Recent developments in the production of electronic display chips enable achievement of higher resolution thermographic images. The main advantage of these devices is real time contactless temperature measurement. Historically, the first thermographic image of man was done by Czerny in 1928 in Frankfurt am Main [9]. First medical use of thermography was reported from Germany in 1952. However, these devices were very expensive and their resolution level was low [34]. Thermography witnessed a boom in many clinical fields in the late 20th century. A detailed review of

\footnotetext{
* Corresponding author. Tel.: +420 549491320.

E-mail address: vbernard@med.muni.cz (V. Bernard).
}

confirmatory current medical applications is presented in the review by Lahiri et al. [22].

Despite of some individual asymmetry of temperature distribution on the body surface and temperature differences between individuals [11,38-40,43] in particular, the diagnostic use of thermography raised promising hopes of beneficial diagnostic possibilities. Zaproudina et al. [45] reviewed studies which dealt also with the reproducibility of the thermographic results. The authors of this paper studied thermal symmetry of people taking also in consideration the possible effect of environmental influences during the measurements.

Thermographic imaging has application potential e.g. in patients with diabetes mellitus. It was found that the diabetic foot syndrome and similar symptoms demonstrate some association with the surface temperature of extremities [6,36,37]. Infrared thermography was used by Bhara et al. for diagnostics of diabetic neuropathy [4]. Huang et al. [19] recently studied patients suffering from peripheral arterial disease. In connection with the measurement of ankle brachial index (ABI), they tried to develop a method for the identification of ischemic limbs. In Japan thermography was used for assessment of blood flow temperature dependence in the extracranial or intracranial bypass [27]. Certain applications have been described also in studies performed on the respiratory tract. For example, it makes possible measurement of the breath volume in nostrils $[23,24]$.

Not only acceptable affordability but also higher resolution supported flourishing of thermographic systems. Unfortunately, 
they were often used by inadequately trained medical staff. It should be emphasized that in thermography it is necessary to consider various influences that may significantly affect the measured temperature values. First, we have to consider the physical properties of the scanned surface such as emissivity or transparence and also the external environmental factors, like the ambient temperature. We have also to consider present external sources of infrared radiation and the radiation background.

In fact, the specific emissivity and reflectivity are fundamental properties of the scanned surfaces [15]. They play an important role in industrial use of thermoimagers, as shown by Holan in outdoor measurement of the thermal insulation of buildings at different air temperatures $[17,18]$. If we focus on medical applications, these properties are absolutely crucial. It is not enough to consider emissivity of human skin as almost identical with the black body model.

The essence of surface temperature measurement by means of the thermocamera is the detection and analysis of infrared radiation emitted from analyzed object and corresponds with its temperature. To understand fundamentals of thermography it is necessary to take into account the Wien's law and StefanBoltzmann law. The Wien's law states, that radiation maximum power emitted by black body at a certain wavelength decreases with increasing thermodynamic temperature (i.e. the warmer the body, the shorter the wavelength or the higher the frequency of emitted radiation):

$\lambda_{\max }=\frac{b}{T}$

where $\lambda_{\max }$ is the wavelength of the of emission maximum, $T$ is the body temperature and $b$ is called Wien's constant $\left(b=2.89878 \times 10^{-3} \mathrm{~m} \mathrm{~K}\right)$.

The Stefan-Boltzmann law states that the total energy $E_{0}$ emitted per unit surface area of a black body per unit time is directly proportional to the fourth power of the black body thermodynamic temperature $T$ :

$E_{0}=\sigma \cdot T^{4}$

where $\sigma$ is the Stefan-Boltzmann constant. It can be derived from other physical constants:

$\sigma=\frac{2 \Pi^{5} k^{4}}{15 c^{2} h^{3}}$

where $k$ is the Boltzmann constant, $h$ is Planck's constant, and $c$ is the speed of light in vacuum. Thus at $100 \mathrm{~K}$ the energy flux density is $5.67 \mathrm{~W} \mathrm{~m}^{-2}$; at $1000 \mathrm{~K}$ it is $56.70 \mathrm{~W} \mathrm{~m}^{-2}$ etc. A body that does not absorb all incident radiation (sometimes denoted as a grey body) emits less energy than a black body and it is characterized by an emissivity, $\varepsilon<1$ :

$E=\varepsilon \cdot \sigma \cdot T^{4}$

In our study only the surface temperature was measured. We took into account the infrared radiation of the measured body, radiation of environment (background) and radiation of the atmosphere. The radiation of the atmosphere can be neglected in measurements on the human body (due to high air transmittance and the short measurement distance). In other words, the resulting value of temperature of the measured body may be affected by mirrored radiation provided by ambient temperature, i.e. by electromagnetic waves reflected from the analyzed area, whose wavelength corresponds with the temperature of surrounding objects and the background. This may be called "the mirrored temperature". Reflected temperature (the mirrored temperature) effect can be eliminated by appropriate choice of emissivity value.

The emissivity of an object is the ratio of the actual amount of infrared energy emitted compared with the theoretically achievable maximum amount of this energy that could be emitted. A physicist defines emissivity as the percent of infrared energy emitted by an object at any given temperature as compared to the theoretically perfect amount of infrared energy emitted by an object at the same temperature. The emissivity of an object is the ratio of the actual amount of infrared energy emitted compared to the theoretically perfect amount that could be emitted. Emissivity is a number ranging from 0 to 1 . An object that emits the maximum possible amount of infrared energy at a given temperature is called a black body or a perfect radiator. It has the emissivity value of 1 (100\%). An object that emits only $80 \%$ of the maximum theoretical amount of infrared energy has an emissivity value of 0.8 .

Emissivity of clean human skin is about 0.98 . This value is a result of many studies done during a time period of 30 years $[7,8,10,13,14,16,20,25,26,30,44]$. Very accurate value was determined by Steketee et al.; they found a value of $0.98 \pm 0.01$ [35]. One of the most recent measurements of emissivity was a study done in 2009 in Mexico using the $\mathrm{CO}_{2}$ laser beam - $0.976 \pm 0.006$ [42].

The temperature measurement can be correct only when the emissivity value is well defined. This is because the measured surface temperature is a function of emissivity. Surface temperature $T$ can be defined according to the physicist Pavelek by using formula [31]:

$T=\sqrt[4]{\frac{\frac{q_{c k}}{\sigma}+T_{\mathrm{amb}}^{4}-(1-\varepsilon) \cdot T_{\mathrm{mir}}^{4}}{\varepsilon}}$

There $T_{\mathrm{amb}}$ - ambient temperature of environment and thermocamera, $T_{\text {mir }}$ - mirrored temperature of other object which is in optical contact with analyzed object, $q_{c k}-$ is the sum of the density of heat flow between the object and thermography equipment.

However, what happens if the human skin is covered with an undefined material or some traces of water? Can it affect the emissivity and hence the measured temperature? These questions are not answered or even addressed in most clinical studies. Usually there is a requirement of only achieving the thermal equilibrium between the skin and the experimental room $[1-3,5,12,29]$. Some authors also take into account the ambient air flow [3]. However, some cold tests were carried out on extremities (immersion in cold water bath) $[3,12]$ without considering that water can affect emissivity of the skin and hence the measured temperature. This is also not taken into account in several studies [19]. Furthermore, in a study aimed at measuring temperature in glaucoma surgery by thermography, high reflectivity of the eye was not taken into account [21]. On the other hand, Sanchez et al. mention the various criteria for emissivity measured with infrared thermography. They were aware of the important fact that the skin is not to be covered by any kind of substance that could affect actual measurement [33].

The aim of the presented work is to determine whether the measurement of hand surface temperature could be affected by a topically applied substance, i.e. whether the measured surface temperature, when using an infrared camera, will be identical with the temperature measured for example by a thermocouple. We need to decide whether it is necessary to ensure absolute cleanliness of the skin during the measurement, i.e. whether it is possible to measure the temperature for example in the course or directly after surgery (considering the presence of a liquid on the surface of the wound, or an application of substances such as ultrasound gel, ointments or disinfectants). In other words, we attempted to 
determine whether the emissivity can be neglected or not in such measurements.

It should also be noted, that namely in medicine situations may occur necessitating the measurement of wet surface temperatures, as in the case of for example fresh wounds.

\section{Materials and methods}

All thermograms were recorded with the infrared camera FLIR B200 (Flir Systems, Danderyd, Sweden) equipped with focal plane array microbolometer thermal detector, $200 \times 150$ IR resolution, spectral range $7.5-13 \mu \mathrm{m}$. The absolute accuracy of the measurement is declared at $\pm 2{ }^{\circ} \mathrm{C}$ or $\pm 2 \%$ of reading. Thermal sensitivity is $0.08{ }^{\circ} \mathrm{C}$.

As the reference a thermocouple probe type K (Fluke, Son, The Netherlands) connected to the multimeter METEX E32 (Metex Corporation, Seoul, Korea) was used. The thermocouple system was calibrated for the temperature range of $0{ }^{\circ} \mathrm{C}-50{ }^{\circ} \mathrm{C}$.

The following commonly used medical topical skin applications were used: the Novikov solution (an antiseptic) consisting of tannin, ethanol, virgin castor oil, brilliant green (viride nitens) and collodion (Fargon a.s., Olomouc, Czech Republic), ultrasound gel Aquasonic 100 (Parker Laboratories, inc., New Jersey, USA). Commercially available Hydration cream (Marks \& Spencer p.l.c., London, UK). For topical application onto an aluminum plate, a skin ointment Pferdebalsam (Herbamedicus, Zürich, Switzerland) was used.

\section{Measurement of surface temperature of hands}

It needs to be emphasized that the essential aim of the experiments was not absolute measurement of surface temperature, but the comparison of the measured surface temperature differences between topically treated and non-treated surfaces. We obtained thermograms always from both upper limbs at a constant distance of $1.5 \mathrm{~m}$ by using the thermal camera. The images were taken for each hand before applying substances to the skin, always at ambient temperature of $23{ }^{\circ} \mathrm{C}$, under following illumination conditions: daylight, incandescent lamp light and light of fluorescent lamps. A control thermoimage of non-affected hands was also recorded at ambient mirrored temperature of $5{ }^{\circ} \mathrm{C}$ with the hands were still located in a room with temperature of $23^{\circ} \mathrm{C}$ in the course of this measurement. The analyzed surface area of hands was oriented perpendicularly to the axis of the objective of the camera during all measurements. Approximate dimensions of analyzed areas on the hands were $2000 \mathrm{~mm}^{2}$.

Consequently, a substance was applied on the skin of one right hand (ultrasound gel, water, Novikov solution, Hydration cream). All of the applied substances had the room temperature of $23{ }^{\circ} \mathrm{C}$. They were applied in thin uniform layer to the dorsal side of the hand using a spatula or dropper. The skin of the second (reference) hand was treated (touched) in the same way with a spatula without the studied compounds. Measurements of the surface temperatures of affected and unaffected hands were performed immediately thereafter. The same conditions of room temperature and mirrored temperature were maintained during the measurements. Subsequent measurement was made after 10 min (Hydration cream) or $30 \mathrm{~min}$ (ultrasound gel and Novikov solution) when the applied substances dried out or soaked into the skin. Water at body surface temperature $\left(35^{\circ} \mathrm{C}\right)$ was applied to the hand. On the camera, the value of emissivity was always set the same for all measurements. It was a value tabulated for human skin in the FLIR user's manual $(\varepsilon=0.98)$. The presented outputs were from the hands of a healthy Caucasian 25 year-old male, further comparative studies confirming the presented results were made.

\section{Measurement of surface temperature of aluminum plate}

An aluminum plate with dimensions $180 \times 220 \times 5 \mathrm{~mm}$ with a mechanically cleaned (abraded) surface was kept at a room temperature of $23^{\circ} \mathrm{C}$. Its surface was then covered with the ultrasound gel, Hydrating cream and skin ointment. The layer thickness corresponded to thickness of normal topical skin application. The treated aluminum plate was left at room temperature until the applied substances dried. The surface temperatures of the treated and untreated areas of the aluminum plate were measured by means of thermal camera before application, immediately after that and after drying of applied substances. This measurement was done at the room temperature, mirrored ambient temperature was $23^{\circ} \mathrm{C}$ or $-2{ }^{\circ} \mathrm{C}$. A uniform emissivity was set for the entire series of images recorded during the measurement. The real object temperature was measured by means of a thermocouple and did not change during the measurements.

The measurement under mirrored ambient temperature was done according to the following design: The initial measurement was done in the room under room temperature. Following measurement was done in the same position in the same place but with opening windows and opening of the window blind. This assured that the plate was in the room temperature; the ambient temperature was mirrored due to electromagnetic waves passing through window. The infrared camera was placed in a holder at distance of $1.5 \mathrm{~m}$ from the plate for reasons of the optical width of lens.

\section{Image processing}

The obtained thermoimages were processed using FLIR QuickReport 1.2 (Flir Systems, Danderyd, Sweden) software. All images were standardized to the same temperature range of $20^{\circ} \mathrm{C}-40{ }^{\circ} \mathrm{C}$ and converted to gray scale by the software. The same value of emissivity was used for all images or for all of their analyzed parts, $\varepsilon=0.98$. Furthermore histograms of selected areas from the thermoimages were obtained by using Image $1.45 \mathrm{~s}$. The selected areas from images had size exceeding 5000 pixels, i.e. the statistical data were obtained from more than 5000 point temperature measurements. In this way obtained data (always including controls, i.e. untreated surface of the hand and the surface of the treated hand) were compared to each other. The thermoimages were presented in standard medical format using the rainbow scale.

\section{Statistical evaluation}

The obtained data represent individual surface temperature maps of the selected hands. These data were tested for normality by use of STATISTICA 10 (StatSoft CR s.r.o., Prague, Czech Republic) software using Kolmogorov-Smirnov test or by plotting $P-P$ graphs or $Q-Q$ graphs. They were also tested for statistical difference by means of a paired t-test or in the case of adequacy by Mann-Whitney test on significance level of $p=0.05$ (the treated hand and control hand surface temperature, or left and right hand surface temperatures were always tested). All sets of the obtained data were tested for normality and subsequently the adequate testing process was chosen. We also took into account the sensitivity of the FLIR B200 device and the reported measurement error when determining the identity or difference between data sets. For each analyzed area, we determined the standard deviation, minimum and maximum values of the gray scale which corresponded to the selected temperature range. These values were then converted to temperature and presented in the work as follows. The difference of mean value of surface temperatures of right and left hand found in control measurements was considered as the measurement error. We assume this value can be considered as the limit for determining the significance of the differences. 
Table 1

Aluminum surface temperature, ambient and mirrored temperature $23{ }^{\circ} \mathrm{C}$ Data in ${ }^{\circ} \mathrm{C}$.

\begin{tabular}{lllll}
\hline Covering substance & Mean value & s.d. & Max. & Min. \\
\hline None & 23.0 & 0.2 & 23.7 & 22.5 \\
Skin ointment & 22.1 & 0.3 & 23.0 & 21.3 \\
Hydration cream & 21.7 & 0.2 & 22.7 & 21.4 \\
Ultrasound gel & 21.5 & 0.2 & 22.2 & 21.0 \\
\hline
\end{tabular}

\section{Results}

\section{Aluminum plate}

This measurement was done to assess the influence of emissivity and the mirrored temperature on the resulting surface temperature data. The results of measurements of surface temperature of aluminum plate clearly show the effect of ambient temperature mirroring.

The aluminum plate with a clean surface has a uniform surface temperature distribution. The same plate with surface treated by various substances appeared to have different surface temperatures, related to the applied substance. The results of measurements, when the room temperature and the ambient mirrored temperature were equal $\left(23^{\circ} \mathrm{C}\right)$, are shown in Table 1 . The table shows surface temperatures as mean values, standard deviations (s.d.), maximum and minimum values from analyzed area for different surface coatings - untreated aluminum, skin ointment, Hydration cream and ultrasound gel. The surface temperature was measured after the applied substances dried out. The surface of aluminum plate treated with ultrasound gel or ointment had lower temperatures than the untreated aluminum surface. More significant change of thermographic temperature occurred in the plate which was measured under condition of mirrored ambient temperature below $-2{ }^{\circ} \mathrm{C}$ in drying state. (Table 2.).

As shown in Fig. 1, there is a visible decrease of temperature for all surfaces under ambient temperature of $23^{\circ} \mathrm{C}$ as well as under mirrored temperature $-2{ }^{\circ} \mathrm{C}$. It is evident especially on untreated aluminum surface, where the mean value is about $0{ }^{\circ} \mathrm{C}$. Real aluminum temperatures measured by the thermocouple are the same for both cases of mirrored ambient temperatures $\left(23{ }^{\circ} \mathrm{C}\right.$ or $\left.-2{ }^{\circ} \mathrm{C}\right)$. The temperatures measured by thermocamera are different (in the case od $23{ }^{\circ} \mathrm{C}$ or $-2{ }^{\circ} \mathrm{C}$ ), because a fixed setting of emissivity in thermocamera corresponding to the value of human skin 0.98 was used.

\section{Skin surface}

The results show surface temperature of hand depending on various topically applied substances: ultrasound gel, water, and Novikov solution at various mirrored temperatures (room temperature of $23^{\circ} \mathrm{C}$ and outdoor temperature of $5{ }^{\circ} \mathrm{C}$ ).

\section{Control measurement}

The results show surface temperatures of left and right hand without any applied substances (Table 3.).

\section{Table 2}

Aluminum surface temperature, ambient temperature $23{ }^{\circ} \mathrm{C}$ and mirrored temperature $-2{ }^{\circ} \mathrm{C}$. Data in ${ }^{\circ} \mathrm{C}$.

\begin{tabular}{lcccr}
\hline covering substance & Mean value & s.d. & Max. & Min. \\
\hline None & 0.2 & 0.8 & 2.1 & -1.5 \\
Skin ointment & 15.3 & 1.7 & 17.1 & 3.9 \\
Hydration cream & 15.9 & 0.9 & 17.2 & 11.8 \\
Ultrasound gel & 16.1 & 0.4 & 16.7 & 15.3 \\
\hline
\end{tabular}

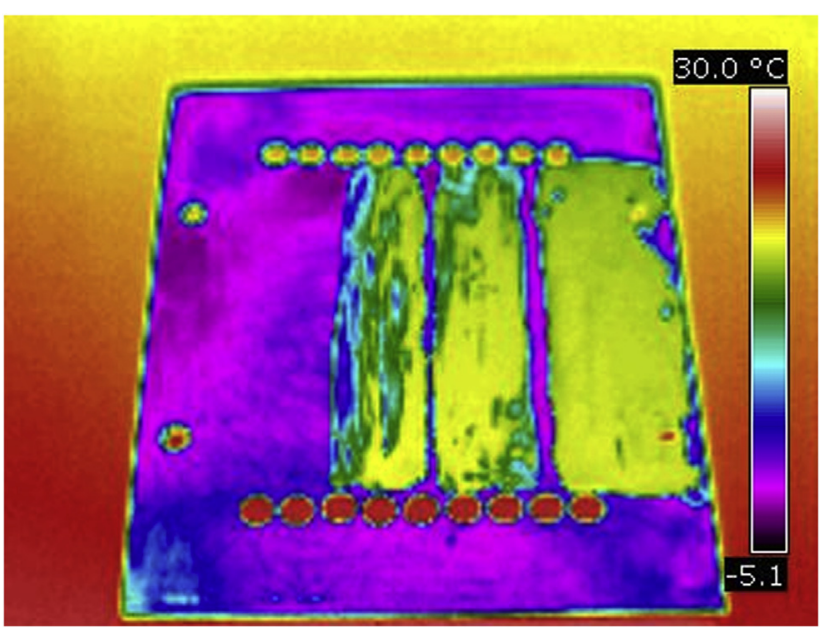

Figure 1. Thermogram of aluminum plate with (from left to right) an ointment, hydration cream, ultrasound gel at mirrored ambient temperature of $-2{ }^{\circ} \mathrm{C}$.

The values in Table 3. show the temperature differences $\Delta$ between the left and right hand with a maximum value of 0.35 . The surface temperatures are almost exactly the same in all cases, only slightly lower for the mirrored ambient temperature of $5{ }^{\circ} \mathrm{C}$. This value of maximal difference $\Delta$ between left and right hand surface temperature is considered as the error of measurement for subsequent measurement evaluation.

The histograms of surface temperature from selected areas showed distribution of data compared with the curve of normal distribution with an almost identical value of standard deviation for each option of mirrored ambient temperature, as is seen in Fig. 2a and Fig. 3a.

\section{Ultrasound gel application}

The results obtained after the application of ultrasound gel onto the skin are seen in Tables 4 and 5 . There is an apparent difference between control samples and surface treated samples. A very significant decrease of surface temperature was found in the case of measurements with ultrasound gel in wet state. There is a decrease of surface temperature by more than $4{ }^{\circ} \mathrm{C}$ of the topically treated surface. The greatest decrease in the surface temperature was found in the sample measured under conditions of a mirrored ambient temperature of $5{ }^{\circ} \mathrm{C}$. The difference value $\Delta$ is $4.86{ }^{\circ} \mathrm{C}$ in this case.

A small decrease of surface temperature was also found in the measurement with ultrasound gel in dry state. The maximal $\Delta$

\section{Table 3}

Unaffected skin surface temperature. Data are presented in ${ }^{\circ} \mathrm{C}$. Values of temperature were obtained under following conditions: mirrored ambient temperature of $23{ }^{\circ} \mathrm{C}$, mirrored ambient temperature of $5{ }^{\circ} \mathrm{C}$, incandescent lamp light illumination (bulb), fluorescence lamp illumination (fluor. tube). The table shows mean values, minimal and maximal values and standard deviations (s.d.) of temperatures of measured areas. $\Delta$ means temperature difference between left and right hand.

\begin{tabular}{llllll}
\hline Non-treated skin & \multicolumn{7}{l}{} \\
\hline Sample $/{ }^{\circ} \mathrm{C}$ & Mean & s.d. & Max. & Min. & $\Delta$ \\
\hline Left hand $23{ }^{\circ} \mathrm{C}$ & 33.1 & 0.5 & 34.5 & 31.4 & \\
Right hand $23{ }^{\circ} \mathrm{C}$ & 32.7 & 0.5 & 33.5 & 31.0 & 0.4 \\
Left hand $5{ }^{\circ} \mathrm{C}$ & 32.3 & 0.5 & 33.4 & 30.3 & \\
Right hand $5{ }^{\circ} \mathrm{C}$ & 31.9 & 0.7 & 33.8 & 29.8 & 0.6 \\
Left hand bulb & 33.4 & 0.4 & 34.5 & 32.0 & \\
Right hand bulb & 33.2 & 0.4 & 34.6 & 31.6 & 0.2 \\
Left hand fluor. tube & 33.4 & 0.5 & 34.7 & 31.8 & \\
Right hand fluor. tube & 33.1 & 0.4 & 33.8 & 31.3 & 0.3 \\
\hline
\end{tabular}



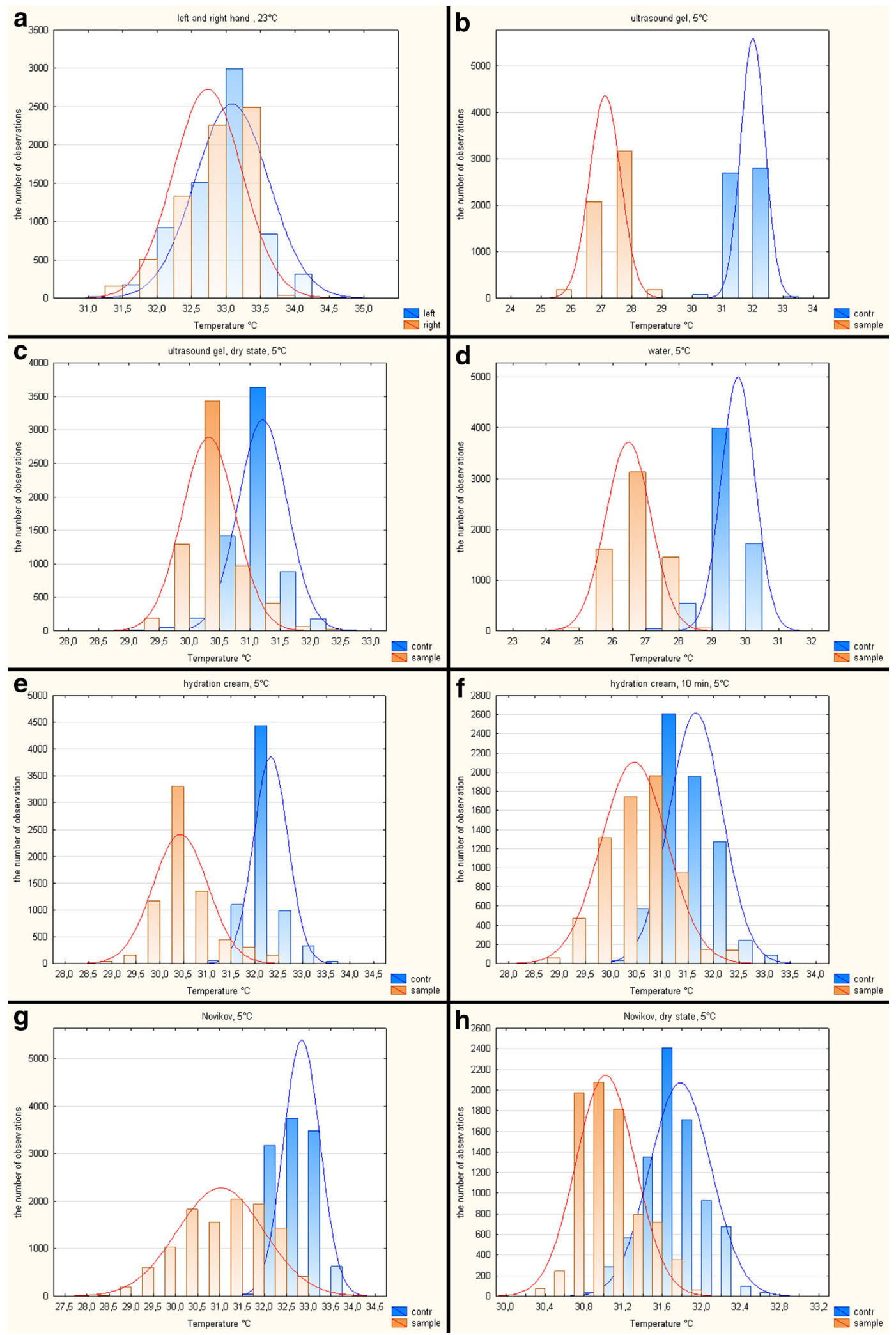

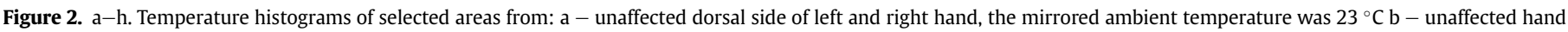

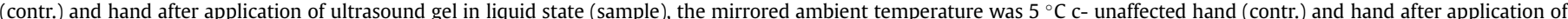

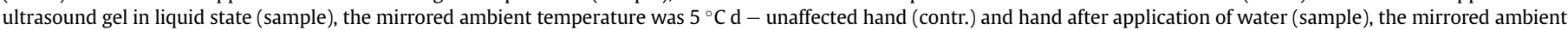

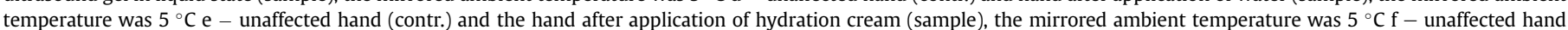

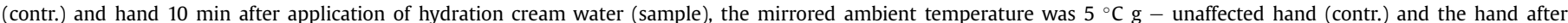

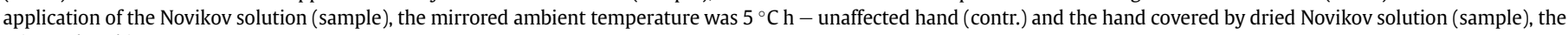
mirrored ambient temperature was $5{ }^{\circ} \mathrm{C}$. 

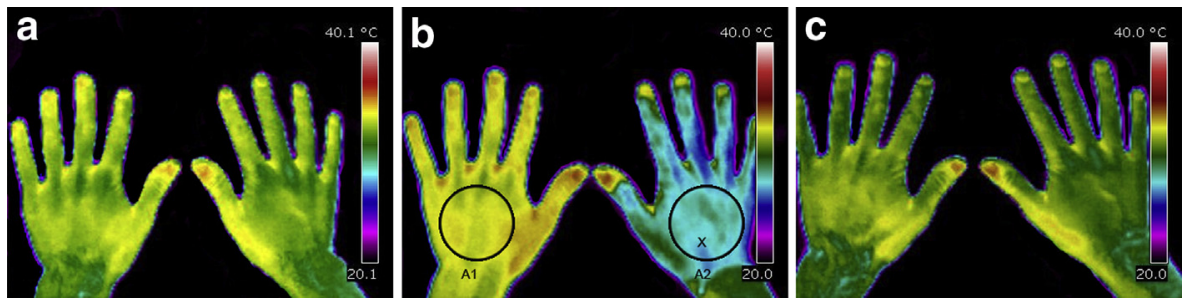

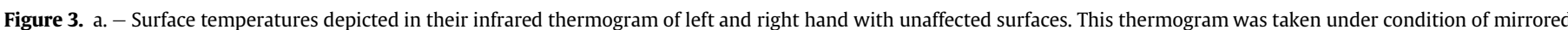

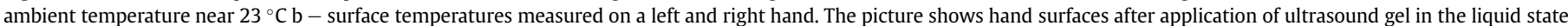

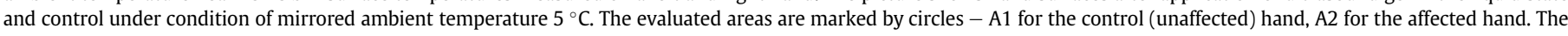

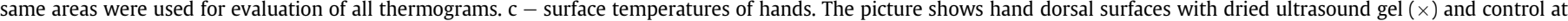
mirrored ambient temperature of $5{ }^{\circ} \mathrm{C}$. The brightness of the background was modified.

value of $0.89{ }^{\circ} \mathrm{C}$ was measured in the sample at a mirrored ambient temperature of $5{ }^{\circ} \mathrm{C}$. All values of $\Delta$ are higher than the error of measurement obtained from Table 3 .

The evaluation of surface temperature histograms of selected areas is presented in Fig. $2 \mathrm{~b}$ and $\mathrm{c}$ in relation to the Fig. $3 \mathrm{~b}$ or $3 \mathrm{c}$. The data were tested for statistical significance for each pair: control and application of ultrasound gel. The results show, that there are statistically significant differences for each pair at both values of mirrored temperatures.

Water application. The surface temperatures are collated in Table 6. The temperature drop is obvious in all of the treated areas. When using data (Fig. 2d) from Table 6 for the $M-W$ test, significant statistical differences for all the tested pairs were found.

Hydration cream application. The values of skin surface temperature after application of Hydration cream are shown in Table 7. It is obvious that application of Hydration cream affects the value of surface temperature not just immediately after application, but also at $10 \mathrm{~min}$ later. There is statistical difference between treated and untreated hand surfaces, namely under conditions of $5{ }^{\circ} \mathrm{C}$ as a mirrored ambient temperature.

The statistical analyses showed significant differences for all pairs of hands for all used experimental designs. The histograms in Fig. 2e and $f$ showed the shift of mean temperature value immediately after topical application as well as 10 min later for the mirrored ambient temperature of $5{ }^{\circ} \mathrm{C}$. The surface temperature difference between the affected and unaffected hands is clearly visible in Fig. 2e or $\mathrm{f}$. There is a typical decrease of temperature of the left hand area. The temperature of hand surface was measured by a thermocouple and the readings were the same for both hands all time. Difference was detected only by infrared camera, meaning only by detection of produced or reflected electromagnetic waves.

Solution Novikov. The skin treated by the Novikov solution was compared with the untreated skin as well - see Table 8.

Table 4

Skin surface temperature after application of ultrasound gel in liquid state. Mirrored ambient temperature of $23{ }^{\circ} \mathrm{C}$ or $5{ }^{\circ} \mathrm{C}$, see also description of previous tables. $\Delta$ means temperature difference between left and right hand. $\bullet$ means statistical significance at $p<0.05$ by using Mann-Whitney test.

\begin{tabular}{lllllll}
\hline sample $/{ }^{\circ} \mathrm{C}$ & Mean & s.d. & Max. & Min. & $\Delta$ & $M-W$ test \\
\hline $23{ }^{\circ} \mathrm{C}$ contr. & 32.8 & 0.4 & 33.7 & 31.9 & & \\
$23{ }^{\circ} \mathrm{C}$ application & 28.3 & 0.5 & 30.2 & 26.9 & 4.5 & $\bullet$ \\
$5{ }^{\circ} \mathrm{C}$ contr. & 32.0 & 0.4 & 33.2 & 30.6 & & \\
$5{ }^{\circ} \mathrm{C}$ application & 27.1 & 0.5 & 28.4 & 25.4 & 4.9 & $\bullet$ \\
Bulb contr. & 32.8 & 0.4 & 34.0 & 31.9 & & \\
bulb application & 28.6 & 0.6 & 30.5 & 26.9 & 4.2 & $\bullet$ \\
Fluor. tube contr. & 32.8 & 0.4 & 33.9 & 31.7 & & \\
Fluor. tube application & 28.4 & 0.6 & 30.5 & 26.5 & 4.4 & $\bullet$ \\
\hline
\end{tabular}

The maximum difference was found in the measurement done immediately after topical application of the solution at an ambient temperature of $23{ }^{\circ} \mathrm{C}$. All presented difference values $\Delta$ were statistically significant. Only the measurement done at the ambient temperature of $23^{\circ} \mathrm{C}$ after $30 \mathrm{~min}$ (dried Novikov solution) showed a difference $\left(0.28^{\circ} \mathrm{C}\right)$ smaller than the difference referred to as the error of measurement (Table 3.) in the control samples.

The histograms of surface temperatures in these thermograms are plotted in Fig. $2 \mathrm{~g}$ and $\mathrm{h}$ and there is clearly higher difference of surface temperatures for immediate measurement after application compared with measurements carried out after $30 \mathrm{~min}$.

\section{Discussion}

Authors attempted to answer the question whether topically applied substances to skin surface can influence the temperature as measured by infrared camera. To answer the question, it was necessary to make a series of experiments during which the skin was treated by various substances commonly used in patients. The authors were aware, that the substances used in experiments had to be at human body temperature (to avoid excessive cooling of the skin), but to simulate situations that may occur during surgery or medical treatment (such as wound washing, disinfection, rubbing in of the ointments), it is common to apply substances at the ambient (room) temperature. In the case of dried-out state of applied substances, after elapse of some time, we can say that the temperature of this topical substance is the same as the skin temperature. The thermal equilibrium occurs very early, because very small volumes of substances are applied. The real temperature of skin was measured by a thermocouple and it is evident, that there were minimal changes of temperature between the topically treated hand and unaffected skin surfaces. Possible explanation of cooling is due to evaporation of solutions immediately their application. This situation is typical for ultrasound gel or the Novikov solution, because of presence of water or ethanol in solution. No possibility of evaporation effect was for affected surfaces when the applied solutions dried out.

Table 5

Skin surface temperature after application of ultrasound gel - dry state. Mirrored ambient temperature of $23^{\circ} \mathrm{C}$ or $5^{\circ} \mathrm{C}$, see also description of previous tables.

\begin{tabular}{lllllll}
\hline sample $/{ }^{\circ} \mathrm{C}$ & Mean & s.d. & Max. & Min. & $\Delta$ & $M-W$ test \\
\hline $23{ }^{\circ} \mathrm{C}$ contr. & 33.0 & 0.4 & 34.1 & 31.9 & & \\
$23^{\circ} \mathrm{C}$ application & 32.2 & 0.4 & 33.1 & 30.7 & 0.8 & $\bullet$ \\
$5{ }^{\circ} \mathrm{C}$ contr. & 31.2 & 0.4 & 32.6 & 29.1 & & \\
$5{ }^{\circ} \mathrm{C}$ application & 30.3 & 0.4 & 32.3 & 28.5 & 0.9 & $\bullet$ \\
Bulb contr. & 32.8 & 0.3 & 33.8 & 31.6 & & \\
Bulb application & 32.0 & 0.5 & 32.8 & 30.4 & 0.8 & $\bullet$ \\
Fluor. tube contr. & 32.9 & 0.4 & 33.8 & 31.9 & & \\
Fluor. tube application & 32.2 & 0.5 & 33.1 & 30.6 & 0.7 & $\bullet$ \\
\hline
\end{tabular}


Table 6

Skin surface temperature after application of water. Mirrored ambient temperature of $23^{\circ} \mathrm{C}$ or $5{ }^{\circ} \mathrm{C}$, see also description of previous tables.

\begin{tabular}{lllllll}
\hline sample $/{ }^{\circ} \mathrm{C}$ & Mean & s.d. & Max. & Min. & $\Delta$ & $M-W$ test \\
\hline $23{ }^{\circ} \mathrm{C}$ contr. & 31.1 & 0.6 & 32.7 & 27.9 & & \\
$23{ }^{\circ} \mathrm{C}$ application & 27.6 & 0.6 & 28.9 & 26.2 & 3.5 & $\bullet$ \\
$5{ }^{\circ} \mathrm{C}$ contr. & 29.7 & 0.5 & 30.8 & 27.7 & & \\
$5{ }^{\circ} \mathrm{C}$ application & 26.5 & 0.7 & 28.2 & 24.5 & 3.4 & $\bullet$ \\
Bulb contr. & 30.9 & 0.6 & 32.7 & 29.7 & & \\
Bulb application & 27.8 & 0.6 & 29.0 & 26.4 & 3.1 & $\bullet$ \\
Fluor. tube contr. & 31.0 & 0.6 & 32.7 & 28.5 & & \\
Fluor. tube application & 27.8 & 0.6 & 29.3 & 26.5 & 3.2 & $\bullet$ \\
\hline
\end{tabular}

The measured surface temperature is attributable partly to infrared radiation from skin/tissue, partly from the used solutions and also from mirroring of ambient space. All these radiations correspond with real temperatures of these individual radiation sources. We can neglect the air, because its absorption of electromagnetic waves for a distance of $1.5 \mathrm{~m}$ is minimal. In the case of identical temperatures of tissue and topically applied substances we can also ignore their thermal effect. In cases of different temperatures of the skin and applied substances (immediately after application), the substances have a minimal thermal effect due to their thin layer as compared to thickness of the covered tissues. Despite of evaporation, the change of surface temperature can be (seemingly) caused by reflected IR radiation, i.e. by mirrored temperature from ambient medium. This is extremely important for substances in thermal equilibrium with the skin.

If we take into consideration only the skin, the problem is relatively simple because of its emissivity value of 0.98 . In this case, there is minimal effect of mirrored temperature. However, if we use materials with lower emissivity value, the measured temperature readings will be higher or lower due to mirrored temperature. The value of mirrored temperature depends on real temperature of environment. This is obvious from the experiment with aluminum plates (see Fig. 1). The real temperature of aluminum plate and all applied substances was $23{ }^{\circ} \mathrm{C}$, but the surface temperature of aluminum seemed lower in comparison to substances topically applied to the aluminium surface. This is caused by lower emissivity coefficient of aluminum than is the emissivity coefficient of oil and other applied substances. Therefore, aluminum reflects the ambient temperature $-2{ }^{\circ} \mathrm{C}$ and so appears to be colder than it really is.

A similar effect is present in the case of human skin with topically applied substances which have lower value of emissivity coefficient compared to skin. This results in their increased reflectance of IR radiation provided by the ambient temperature. Because it was lower than temperature of skin, the surface temperature of affected hand seemed also lower. This effect, due to different emissivity of surface of topically treated hands compared with untreated hands, was most pronounced under conditions of mirroring of the lowest temperature, in our case $5{ }^{\circ} \mathrm{C}$. This set-up simulates the situation in a thermally tempered room near an

Table 7

Skin surface temperature after application of hydration cream. Mirrored ambient temperature of $23{ }^{\circ} \mathrm{C}$ or $5{ }^{\circ} \mathrm{C}$, see also description of previous tables.

\begin{tabular}{lllllll}
\hline sample $/{ }^{\circ} \mathrm{C}$ & Mean & s.d. & Max. & Min. & $\Delta$ & $M-W$ test \\
\hline $23{ }^{\circ} \mathrm{C}$ contr. & 33.4 & 0.2 & 33.9 & 32.5 & & \\
$23{ }^{\circ} \mathrm{C}$ application & 32.4 & 0.3 & 33.8 & 31.0 & 1.0 & $\bullet$ \\
$5{ }^{\circ} \mathrm{C}$ contr. & 32.3 & 0.3 & 33.7 & 31.3 & & \\
$5{ }^{\circ} \mathrm{C}$ application & 30.4 & 0.6 & 32.4 & 28.8 & 1.8 & $\bullet$ \\
Hydration cream & measured & 10 min & after application & & \\
$23{ }^{\circ} \mathrm{C}$ contr. & 33.0 & 0.4 & 33.6 & 31.9 & & \\
$23{ }^{\circ} \mathrm{C}$ application & 31.9 & 0.7 & 34.1 & 30.6 & 1.1 & $\bullet$ \\
$5{ }^{\circ} \mathrm{C}$ contr. & 31.6 & 0.5 & 33.4 & 30.1 & & \\
$5{ }^{\circ} \mathrm{C}$ application & 30.4 & 0.6 & 32.6 & 28.8 & 1.2 & $\bullet$ \\
\hline
\end{tabular}

Table 8

Skin surface temperature after application of Novikov solution. Mirrored ambient temperature of $23{ }^{\circ} \mathrm{C}$ or $5{ }^{\circ} \mathrm{C}$, see also description of previous tables.

\begin{tabular}{lllllll}
\hline sample $/{ }^{\circ} \mathrm{C}$ & Mean & st. dev. & Max. & Min. & $\Delta$ & $M-W$ test \\
\hline $23{ }^{\circ} \mathrm{C}$ contr. & 34.2 & 0.2 & 34.8 & 33.7 & & \\
$23{ }^{\circ} \mathrm{C}$ application & 30.1 & 2.0 & 34.2 & 26.8 & 4.1 & $\bullet$ \\
$5{ }^{\circ} \mathrm{C}$ contr. & 32.8 & 0.4 & 33.8 & 31.9 & & \\
$5{ }^{\circ} \mathrm{C}$ application & 31.0 & 0.9 & 33.6 & 28.4 & 1.8 & $\bullet$ \\
Novikov - measured after application & 30 min, dry & state & & \\
$23{ }^{\circ} \mathrm{C}$ contr. & 33.5 & 0.4 & 34.6 & 32.4 & & \\
$23^{\circ} \mathrm{C}$ application & 33.2 & 0.3 & 33.8 & 31.9 & 0.3 & $\bullet$ \\
$5{ }^{\circ} \mathrm{C}$ contr. & 31.8 & 0.3 & 32.8 & 30.9 & & \\
$5{ }^{\circ} \mathrm{C}$ application & 31.0 & 0.3 & 31.9 & 30.3 & 0.8 & $\bullet$ \\
\hline
\end{tabular}

open window (or a window with panes made of a thermally conductive material transmitting IR radiation coming from the external environment at a temperature of $5{ }^{\circ} \mathrm{C}$ ).

All values of the difference between treated and untreated hand surfaces were higher than the measurement error determined by comparing temperatures of non-affected hands in dry state. This finding indicates the possibility of erroneous measurements, even in situations, when the skin was topically treated a long time before the measurement. This can be typical in situations such as when applying ointments on burns or skin lesions, and antiseptics on injured or transplanted limbs.

It could also be a problem if we measure the temperature of an unpaired organ, for example during liver transplants [28]. It is of great importance in this case that liver is an organ with a moist surface. There will certainly be some changes in emissivity due the water on the surface (plus the effect of evaporation). However, the authors of the study do not mention the value of used emissivity coefficient. The same situation may be found in a study of heart structure where the authors also do not mention the value of used emissivity [41]. It can be assumed that the heart was treated with saline solution and its surface was wet.

There is no need to consider changes in their respective emissivity, when we are only comparing temperatures of symmetrical body parts, and do not attempt to correctly determine the absolute temperature as is the case in the study of Rich et al. [32]. However, certain differences between the right and left limb temperatures were observed even in our measurements. It proves that there is a small thermal lateral difference between the distal parts of the body (in our experiment lower than $0.5^{\circ} \mathrm{C}$ ) which can be considered as the measurement error.

The proposed correction of emissivity values is valid for the used FLIR thermal camera and the specific described situations, but it could prove useful for skin thermoimages in general. The values obtained by the measurement certainly depend on the accurate value of the difference between tissue/substance temperature and the ambient temperature.

It is always also necessary to take into account the cooling effect due to evaporation. This effect was measured also by means of a thermocouple. In the case of immediate temperature measurements, this phenomenon must be considered. For example, it is clearly evident at high values of temperature differences after application of Novikov solution $\left(\Delta=4.13^{\circ} \mathrm{C}\right)$. However, it is not possible to explain in this way the changes of the surface temperature for longer time intervals after substance application as confirmed by thermocouple. Thus, the respective difference of temperature reading was caused only by different emissivity.

\section{Conclusions}

It is quite possible to produce erroneous infrared camera body surface temperature measurements without underlying knowledge 
of some physical context. The topical application of substances to the skin may influence the value of surface temperature readings. The need of temperature correction is irrelevant when determining the temperature difference of paired organs. Where it is necessary to determine the absolute surface temperatures, it is essential to know the emissivity of the surface parameters or reflected ambient temperature. In the carried out experiments we found no effects on our measurements if we used incandescent or fluorescent lighting in the experimental environment. This finding may be also of some importance for thermography performed under artificial lighting conditions, as is often the cause in medical situations.

The IR camera seems to be useful equipment for measurement of surface temperature in medicine and biology of today and in future, because it allows very safe contactless measurement. This is one of the main advantages compared to other methods of temperature measurement such as thermocouple, together with the possibility of evaluation of the average surface temperature. However, it is necessary to know all possible sources of errors during infrared camera measurements to exploit the advantages of this technique. After proper handling of the issues associated with determining of emissivity, the thermal camera could be used also for measuring absolute temperatures. Without question it is ideal for comparison of temperatures of two areas, for example paired organs because there is no need for knowing the emissivity. It is not necessary to consider the reflected temperature in the case of clean skin, due to its high value of emissivity which guarantees minimum reflection of ambient temperature. On the other hand we must correct the surface temperature due to changes of emissivity in the case of skin topically treated with an ointment, gel or solution. If not performed, we face the risk of obtaining biased measured data with a great margin of error, namely in situations where the reflected ambient temperature differs substantially from the temperature of the measured tissue.

\section{Conflict of interest statement}

No conflict of interest, financial or other, exists.

\section{Acknowledgments}

The authors would like to express their gratitude to Ing. Dušan Sušil for his help during the process of construction of the software algorithm used for thermoimage processing.

\section{References}

[1] Ammer K, Melnizky P, Rathkolb O, Ring EF, IEEE. Thermal imaging of skin changes on the feet of type II diabetics. In: 23rd annual international conference of the IEEE-engineering-in-medicine-and-biology-society. Istanbul, Turkey: IEEE; 2001. p. 2870-2.

[2] Bagavathiappan S, Philip J, Jayakumar T, Raj B, Rao PN, Varalakshmi M, et al. Correlation between plantar foot temperature and diabetic neuropathy: a case study by using an infrared thermal imaging technique. Journal of Diabetes Science and Technology 2010;4(6):1386-92.

[3] Bagavathiappan S, Saravanan T, Philip J, Jayakumar T, Raj B, Panicker TM, et al. Investigation of peripheral vascular disorders using thermal imaging. The British Journal of Diabetes \& Vascular Disease 2008;8(2):102-4.

[4] Bharara M, Cobb J, Claremont D. Thermography and thermometry in the assessment of diabetic neuropathic foot: a case for furthering the role of thermal techniques. The International Journal of Lower Extremity Wounds 2006;5(4):250-60.

[5] Bharara M, Viswanathan V, Cobb JE. Cold immersion recovery responses in the diabetic foot with neuropathy. International Wound Journal 2008;5(4):562-9.

[6] Boyko EJ, Ahroni JH, Stensel V, Forsberg RC, Davignon DR, Smith DG. A prospective study of risk factors for diabetic foot ulcer. The Seattle Diabetic Foot Study. Diabetes Care 1999;22(7):1036-42.

[7] Buchmüller K. Über die ultrarote Emission, Reflexion und Durchlässigkeit der lebenden menschlichen Haut im Spektralbereich $\lambda \approx 3-15 \mu \mathrm{m}$. Pflügers Archiv European Journal of Physiology 1961;272(4):360-71.
[8] Büttner K. Über die Wärmestrahlung and die reflexionseigenshaften der Menschlichen Haut. Strahlentherapie 1937;58:345-60.

[9] Czerny M. Über Photographie im Ultraroten 25. Physik 1929;53:1.

[10] Derksen WL, Monahan TI, Lawes AJ. Automatic recording reflectometer for measuring diffuse reflectance in the visible and infrared regions. The Journal of the Optical Society of America 1957;47:995-9.

[11] Feldman F, Nickoloff EL. Normal thermographic standards for the cervicalspine and upper extremities. Skeletal Radiology 1984;12(4):235-49.

[12] Fujiwara Y, Inukai T, Aso Y, Takemura Y. Thermographic measurement of skin temperature recovery time of extremities in patients with type 2 diabetes mellitus. Expermental and Clinical Endocrinology \& Diabetes 2000;108(7):463-9.

[13] Gärtner W, Göpfert H. Topographische Untersuchungen über die Strahlungseigenschaften der lebenden menschlichen Haut. Pflügers Archiv European Journal of Physiology 1964;280(3):224-35.

[14] Gärtner W, Ling K, Göpfert H. Über die Abhängigkeit der Temperaturstrahlung der lebenden menschlichen Haut von der Durchblutung. Pflügers Archiv European Journal of Physiology 1964;280(3):236-42.

[15] Hackforth HL. Infrared radiation. New York: McGraw Hill; 1960.

[16] Hardy JD, Muschenheim C. The radiation of heat from the human body. IV. The emission, reflection, and transmission of infra-red radiation by the human skin. Journal of Clinical Investigation 1934;13(5):817-31.

[17] Hollan J. Termografické zjištování tepelných vlastností budov in situ (zjištování emisivit a tepelných toků pomocí termokamery). In: Workshop NDT 2004 non-destructive testing. Brno: Brno University of Technology; 2004

[18] Hollan J. Termografické ověřování tepelně izolačních vlastností oken se speciálními roletami. In: Workshop NDT 2005 non-destructive testing. Brno: Brno University of Technology; 2005. p. 25-7.

[19] Huang CL, Wu YW, Hwang CL, Jong YS, Chao CL, Chen WJ, et al. The application of infrared thermography in evaluation of patients at high risk for lower extremity peripheral arterial disease. Journal of Vascular Surgery 2011;54(4):1074-80.

[20] Jacquez JA, Huss J, McKeehan W, Dimitroff JM, Kuppenheim HF. Spectra reflectance of human skin in the region 0.7-2.6mu. Journal of Applied Physiology 1955;8(3):297-9.

[21] Kawasaki S, Mizoue S, Yamaguchi M, Shiraishi A, Zheng X, Hayashi Y, et al. Evaluation of filtering bleb function by thermography. British Journal of Ophthalmology 2009;93(10):1331-6.

[22] Lahiri BB, Bagavathiappan S, Jayakumar T, Philip J. Medical applications of infrared thermography: a review. Infrared Physics \& Technology 2012;55: 221-35.

[23] Lewis GF, Gatto RG, Porges SW. A novel method for extracting respiration rate and relative tidal volume from infrared thermography. Psychophysiology 2011;48(7):877-87.

[24] Lindemann J, Wiesmiller K, Keck T, Kastl K. Dynamic nasal infrared thermography in patients with nasal septal perforations. American Journal of Rhinology Allergy 2009;23(5):471-4.

[25] Mitchell D, Wyndham CH, Hodgson T. Emissivity and transmittance of excised human skin in its thermal emission wave band. Journal of Applied Physiology 1967;23(3):390-4.

[26] Mitchell D, Wyndham CH, Hodgson T, Nabarro FR. Measurement of the tota normal emissivity of skin without the need for measuring skin temperature. Physics in Medicine and Biology 1967;12(3):359-66.

[27] Okada Y, Kawamata T, Kawashima A, Hori T. Intraoperative application of thermography in extracranial-intracranial bypass surgery. Neurosurgery 2007;60(4):362.

[28] Pabisiak K, Romanowski M, Myslak M, Szydlowski L, Sienko J, Domanski L, et al. Variations in temperature of the donor kidney during cold ischemia time and subsequent assessment of reperfusion using the application of thermovision camera. Transplantation Proceedings 2003;35(6):2157-9.

[29] Papanas N, Papatheodorou K, Papazoglou D, Kotsiou S, Maltezos E. Association between foot temperature and sudomotor dysfunction in type 2 diabetes. Journal of Diabetes Science and Technology 2010;4(4):803-7.

[30] Patil KD, Williams KL. Spectral study of human radiation. Nonionizing Radiation 1954;1:39-44.

[31] Pavelek M, Janotkova E. Teorie a praxe termovizních měření (Thery of thermovision measurement). Brno: TESTO; 2008. p. 1-49.

[32] Rich PB, Dulabon GR, Douillet CD, Listwa TM, Robinson WP, Zarzaur BL, et al. Infrared thermography: a rapid, portable, and accurate technique to detect experimental pneumothorax. Journal of Surgical Research 2004;120(2):163-70.

[33] Sanchez-Marin FJ, Calixto-Carrera S, Villasenor-Mora C. Novel approach to assess the emissivity of the human skin. Journal of Biomedical Optics 2009;14(2):6.

[34] Schwamm E, Reeh J. Die Ultrarotstrahlung des Menschen und seine Molekularspektroskopie. Hippokrates 1953;24:737-42.

[35] Steketee J. Spectral emissivity of skin and pericardium. Physics in Medicine and Biology 1973;18(5):686.

[36] Stess RM, Sisney PC, Moss KM, Graf PM, Louie KS, Gooding GAW, et al. Use of liquid crystal thermography in the evaluation of the diabetic foot. Diabetes Care 1986;9(3):267-72.

[37] Sun PC, Lin HD, Jao SHE, Ku YC, Chan RC, Cheng CK. Relationship of skin temperature to sympathetic dysfunction in diabetic at-risk feet. Diabetes Research and Clinical Practice 2006;73(1):41-6.

[38] Uematsu S. Thermographic imaging of cutaneous sensory segment in patients with peripheral-nerve injury-skin-temperature stability between sides of the body. Journal of Neurosurgery 1985;62(5):716-20. 
[39] Uematsu S, Edwin DH, Jankel WR, Kozikowski J, Trattner M. Quantification of thermal asymmetry. 1. Normal values and reproducibility. Journal of Neurosurgery 1988;69(4):552-5.

[40] Uematsu S, Jankel WR, Edwin DH, Kim W, Kozikowski J, Rosenbaum A, et al Quantification of thermal asymmetry. Part 2. Application in low-back-pain and sciatica. Journal of Neurosurgery 1988;69(4):556-61.

[41] Veikutis V, Mickevicius T, Peckauskas A, Morkunaite K, Rackauskas A, Petrusaite A, et al. Experimental study of using thermovision method in interventive cardiology and cardiac surgery practice. Journal of Electrocardiology 2011;44(2):e33.
[42] Villaseñor-Mora C, Sánchez-Marin FJ, Calixto-Carrera S. An indirect skin emissivity measurement in the infrared thermal range through reflection of a $\mathrm{CO}_{2}$ laser beam. Revista Mexicana de Física 2009;55:387-92.

[43] Wasner G, Schattschneider J, Baron R. Skin temperature side differences - a diagnostic tool for CRPS? Pain 2002;98(1-2):19-26.

[44] Watmough DJ, Oliver R. Emissivity of Human Skin in vivo between 2.0[micro] and 5.4[micro] measured at Normal Incidence. Nature 1968;218:885-6.

[45] Zaproudina N, Varmavuo V, Airaksinen O, Narhi M. Reproducibility of infrared thermography measurements in healthy individuals. Physiological Measurement 2008;29(4):515-24. 